\title{
Productive Uses of Basic Energy and Fuel Transitions in Urban South
} Africa

\author{
David K. Kimemia ${ }^{1} \&$ Harold J. Annegarn ${ }^{1}$ \\ 1 Sustainable Energy Technology and Research (SeTAR) Centre \& Dept. of Geography, Environmental \\ Management and Energy Studies, University of Johannesburg, Auckland Park, South Africa
}

Correspondence: David K. Kimemia, SeTAR Centre, University of Johannesburg, P.O. Box 524, Auckland Park 2006, South Africa. Tel: 27-11-559-1903. E-mail: dkimemia@uj.ac.za

Received: August 19, 2012 Accepted: September 3, 2012 Online Published: September 19, 2012

doi:10.5539/eer.v2n2p103 URL: http://dx.doi.org/10.5539/eer.v2n2p103

\begin{abstract}
Perambulates in low income South African settlements brings to the fore the existence of conventional fuels-driven informal business activities. A deeper investigation reveals an energy sub-sector at various stages of transition and with inherent potential for employment creation and income generation. These productive uses of basic energy have economic importance to township residents in terms of meals provision, local air quality and wealth creation. In Alexandra Township, biomass and coal are used for commercial cooking in makeshift restaurants, mainly in the lower-income areas of the sprawling township. The restaurants serve a common gourmet - tripe, pap, roast corn, beef stew, and chicken feet, and, in some places, traditional beer. Based on interviews with operators of the informal businesses, this article examines the challenges borne by the enterprises and shows that many of the difficulties are caused by lack of adequate energy, both in quality and quantity, and inappropriate premises. Lack of awareness of, and training in business capital mobilization is noted as another handicap. Results further indicate a substantial use of LPG and paraffin in well-off areas, which indicates an on-going energy transition from solid to liquid and gaseous fuels. We conclude that an opportunity exists to provide safe, clean, and cost-effective energy services for accelerated business growth. A model for delivering such energy services, composed of energy technology and operational structure, is proposed for possible implementation by the stakeholders.
\end{abstract}

Keywords: productive energy services, fuel transition, paraffin, LPG, South Africa

\section{Introduction}

Access to appropriate levels of energy services or the lack thereof is an indicator of a country's level of social-economic development. The energy services, which are delivered by an energy carrier and the accompanying technology, should meet domestic and productive needs to assure sustainable communities. In fact, for poor urban communities, it is difficult to separate domestic and productive uses of energy as both are carried out in the vicinity of their domicile. Domestic energy services include cooking, heating and lighting, while among productive needs are the production of goods and services for wealth creation. A total neglect on provision of energy services causes people to remain in archaic lifestyles, while the delivery of only residential energy services fails to spur economic activities. Studies have shown that human welfare, as measured by the Human Development Index (HDI), increases with diminishing returns as the level of modern energy services provided increases (Goldemberg et al., 2004). It therefore behoves local and national civil authorities to prioritise energy provision alongside water, food, health, and education.

It is arguable that a lack of access to appropriate level of energy services is one cause of the slow social economic growth in South Africa. This explains the wide consensus that everybody in South Africa should be given access to basic energy services (Adam, 2010; Department of Minerals and Energy [DME], 2003). National government efforts towards universal energy access have focussed on the residential sector with almost a total disregard on the energy demands of the micro enterprises located at the bottom of urban economic system. In order to have meaningful impact on people's lives, energy access must evolve from traditional focus on residential energy towards a focus on communities and economic development (Shrestha et al., 2006).

The National Energy Act [NEA] (No. 34 of 2008) (South Africa, 2008) purposes “...to ensure that diverse energy resources are available, in sustainable quantities at affordable prices, to the South African economy in 
support of economic growth and poverty alleviation...". To meet this aspiration, the government needs to work with stakeholders to develop future-robust policies that comprise a number of transition pathways - from traditional fuels to modern energy technologies. Transitions between technological systems have been characterised as evolutionary processes, in which change emerges from the selection of new technologies that fit with socioeconomic criteria relating to performance, cost, and familiarity and changing user preferences (Bennet \& Pearson, 2009). The competing issues in energy transition therefore demands a multidisciplinary approach, composed of financial experts, economists, technologists and sociologists.

The massive electrification programmes in different parts of South Africa have not noticeably reduced extreme poverty or reliance on conventional fuels. This is not surprising as a global assessment indicates that "....access to electricity and other modern energy sources though a necessity, is not a sufficient requirement for economic and social development" (International Energy Agency [IEA], 2002). Electrification programmes point of impact is mainly at domestic level where households have access to better lighting and electronics power. Small businesses activities with low power factors may also benefit from the current-limited residential electrical supply. However, efficient use of conventional fuels holds more promise for expansion of heat-intensive micro enterprises such as cooking businesses. Eventually such businesses will grow and translate to use of modern fuels in their day-to-day operations.

The discovery of fire is often considered to be the most important discovery of mankind (Miller \& Tillman, 2008). Taming fire meant productively using combustion of solid fuels that is the foundation on which industrialisation arose. It is noted that virtually all goods and services that characterize modern societal welfare depend on the provision of commercial energy (Haas et al., 2008). Historically, biomass was the first energy harnessed by mankind; however, over the last few hundred years, energy transitions have occurred from wood to coal to oil and natural gas. Indeed the transition from biomass to coal has been equated to "the very essence of modernization" (Smil, 2010). However, in order to bring productive, income generating activities to developing countries, investment will need to focus on various (alternative) energy sources, for thermal and mechanical applications (IEA, 2002). Alternatives considered should meet the following criteria: feasible; renewable; environmentally friendly; affordable; safe (Takama, Lambe, Johnson, \& Arvidson, 2011) and fitting with peoples' preferences. Furthermore, energy transitions must lead to energy sustainability, encompassing the imperatives of adequacy and security (Weijermars, Taylor, Bahn, Das, \& Wei, 2012).

As the old adage goes...poverty is unjust for it befalls a man. The only way to lift a people out of poverty is to teach and encourage them to trade and engage in income generating activities. This is no mean task; however, in cases where people are already engaged in commercial ventures, albeit in a micro way, it is much easier to support and achieve growth in these communities in a shorter time. By 2003 figures, about $40 \%$ of South Africans were rated as living in poverty (Note 1), with about $15 \%$ in desperate bid to survive (Bhorat, van den Berg, \& Aardt, 2012). Such households could emancipate themselves through micro enterprises that are powered with ordinary, inexpensive, and often available fuels.

A study that investigated the energy needs of Small Micro and Medium Enterprises (SMMEs) in Eastern Cape Province identified power outages, low amperage supply, and informal electricity supplies/connections as the main challenges (Rhodes University \& University of Fort Hare, 2008). Low amperage power is an offshoot of the Free Basic Electricity [FBE] programme (DME, 2003) whereby households had to agree to reduced maximum current (5 Amp) power supply as a condition of registration as a beneficiary. This ideally perpetuates poverty and ensures that FBE cannot be used to improve socioeconomics of a beneficiary. However, lack of electricity or intermittent supply does not preclude households from engaging in income generating ventures since this is possible with alternative fuels. It is argued that SMME expansion is crucial to South Africa because all other aspects of orthodox macroeconomic policy have led to massive job losses rather than employment creation (Bond, 2000).

A micro-enterprise usually operates in informal business premises; draws upon domestic energy sources; is not registered for VAT due to low turnovers; lacks trade licences; is undercapitalised; and has fewer than five employees (Meadows, Riley, Rao, \& Harris, 2003). Meadows et al. (2003) notes that such businesses are often neighbourhood-based, and are usually served with conventional forms of energy. Lack of adequate energy is often the major stress for such businesses and it is possible to increase turnover, profitability, and employee level just by improving energy access. This study explores how these businesses can achieve sustained growth and employment creation, focussing on the current energy access situation vis-à-vis the preferred scenario.

In 2006, small enterprises employed $55 \%$ of South Africa's labour force, contributing about $42 \%$ of the total wage bill (Njiro, Mazwai, \& Urban, 2010). However, $87 \%$ of these small businesses were survivalist, mainly 
owned by black Africans. Perhaps this is the reasoning behind an argument that SMMEs make only a weak contribution to the job market because SMMEs do not grow (Rogerson, 2006). Instead of writing off SMMEs as a non-starter, it is important to ponder why there was no growth, what is needed to assure growth, and map out how to sustain growth?

The following questions are further posed in this paper: How can we apply basic energy services to eliminate extreme poverty and transform livelihoods? What energy transition scenario is best suited to survivalist business ventures? How can the rise in SMMEs be consolidated to create an enterprising nation, increasing the numbers of economically active South Africans, and eliminate the culture of dependency on welfarism?

Based on interviews with street vendors in Alexandra Township, Johannesburg, this article characterises the productive uses of conventional fuels in urban townships. Of interest are the baseline energy access situations and the potential transition pathways to a sustainable modern energy future. Strategies for accelerated growth in the conventional fuels-driven business sector are discussed and recommendations given.

\section{Study Area - Alexandra Township}

Located in Region E of the City of Johannesburg, $15 \mathrm{~km}$ from the CBD, and featuring six civic wards, Alexandra Township is an important borough. Add that to the glorious history as the centre of Black resistance against white domination and constant mention in the news due to positives and negatives; one cannot fail to notice Alexandra Township. A closer inspection reveals an enclave with diverse contrasts; parts of urban modernity intermingled with rural backwardness and township lawlessness, and the paradox of belonging to two places at the same time - an urban core (spatially speaking), yet at the periphery in terms of socioeconomic status.

Historically, Alexandra Township is unique as the only Black freehold township in Johannesburg that was not relocated under the apartheid regime. This township is likewise unique for having large sections of the population that are not connected to the electricity grid, despite close spatial location to the urban infrastructure of a modern city, including the affluent Sandton business hub (Kimemia \& Annegarn, 2011). The motivation for choosing the study area arose out of a realisation that a significant number of residents in Alexandra use conventional fuels for productive purposes in micro-enterprises, yet no conclusive studies have been done.

Official estimates place the population of Alexandra at around 400000 (City of Johannesburg, 2012). The population exhibits a youthful structure, low skills base and high unemployment. The population density of Alexandra Township is $\sim 600 \mathrm{~km}^{-2}$, as opposed to $4 \mathrm{~km}^{-2}$ in the neighbouring Linbro Park suburb (Kimemia \& Annegarn, 2011).

The Alexandra population is housed in different types of dwellings, largely dependent on socioeconomic status, ranging from stand-alone brick houses for middle income categories to dense one or two-roomed shacks in informal settlements. The population living in informal dwellings may be reducing, as the government, through the Alexandra Renewal Project (City of Johannesburg, 2012), continues to resettle informal settlers in newly built RDP houses (fully subsidised formal houses).

Multiple fuels are used in Alexandra households, even when connected to the electric grid, with the principal cooking fuel in poorer households being paraffin. In higher income households, paraffin is used as a subsidiary fuel to electricity. Depending on income, suitability and availability, off-grid households may use scavenged or purchased firewood, paraffin, candles and coal for a range of energy related tasks. Of late the government and Eskom (electricity utility) are promoting use of LPG as an alternative to electricity for household cooking. However, LPG demand is yet to catch up, hampered by perceived hazardousness, high cost relative to wood and paraffin, and limited availability in local outlets.

\section{Method}

This project was based on a quantitative research approach. Data was collected through one-on-one interviews with a sample of street vendors who operate cooking businesses in Alexandra Township, a historically Black suburb in Johannesburg, South Africa, characterised by a mixture of formal houses and extensive informal backyard shacks. The interview guide was based on a set of semi-structured questions that probe issues on energy access and business operational details. Convenience sampling is applied in the selection of the study area, while purposive and random sampling was used in the selection of businesses to interview.

The raw data was subjected to summative evaluation for quality assurance, coded and captured in a computable format. The quantitative data was analysed with SPSS and MS Excel programmes, while qualitative responses were subjected to content analysis and reported in descriptive prose. Due to time and budget constraints, the energy used in performance of various tasks was not quantified and therefore an energy balance is not part of this paper. 


\section{Results}

\subsection{Fuel and Combustion Technologies}

All the sampled small and micro enterprises were involved in cooking and catering business activities. The main foods cooked were tripe, pap, chicken, and roasted or boiled maize cobs. When asked what energy sources they deployed in the businesses, a majority $34.1 \%$ of the responses mentioned paraffin followed by firewood (25.0\%) and LPG at $22.7 \%$ (Table 1). Although pollution emissions from solid fuels are significantly higher than from liquid and gaseous fuels, some micro enterprises still use solid fuels due to their lower cost and ease of improvising the combustion technology. Wood is preferred to coal due to its cost-effectiveness, fast cooking, and possibilities of free collection.

Table 1. Energy sources used by street cooking enterprises in Alexandra Township

\begin{tabular}{llcc}
\hline & & \multicolumn{2}{c}{ Responses (multiple) } \\
\cline { 3 - 4 } Energy Sources & N & Percent of responses \\
& Paraffin & 15 & $34.1 \%$ \\
& Coal & 4 & $9.1 \%$ \\
& Firewood & 11 & $25.0 \%$ \\
& Electricity & 4 & $9.1 \%$ \\
Total & LPG & 10 & $22.7 \%$ \\
\hline
\end{tabular}

The findings indicate an on-going fuel transition in the informal cooking enterprises from dirtier solid fuels to the cleaner liquid and gaseous fuels. Indoor and proximate air pollution is an important issue in street cooking businesses, which is a point of contention between street vendors and the neighbourhood community. Electricity is not a significant cooking fuel for street vendors due to its higher cost, lack of grid connection and frequent blackouts. Coal that hitherto provided cooking fuel to Alexandra's street vendors seems to have a diminishing role.

Firepower was a major motivation for choosing the combustion technology. For those using paraffin, the old-type wick stove was the most common appliance. Comparative test results on a range of South African paraffin stoves indicate that this stove delivers more firepower (Table 2), better specific fuel consumption and faster task performance (Makonese, Pembergot-Pigott, Robinson, Kimemia, \& Annegarn, 2012). However, the design of the most widely used make of wick stove has been declared unsafe and banned from manufacture, import or sale in South Africa in terms of a South African National Standard [SANS 1906:2006], due to high frequency of associated fire accidents (National Regulator for Compulsory Specifications, 2009). An approved design of wick stove with safety features, part of those in the referenced comparative tests, is yet to gain a foothold in the market as consumers continue to purchase the old-type illegal design stove from formal and informal outlets. Another determinant for selection of combustion technology was the shape and size of the regular cooking pots. For example, people cooking with the circular-bottom cast iron pots or other large pots preferred to use an open fireplace (Figure 1).

Table 2. Comparative task performance (boiling 5 Litres of water) for two paraffin stoves

\begin{tabular}{lcc}
\hline Parameter & Old-type paraffin wick stove (widely used) & Approved paraffin wick stove \\
\cline { 2 - 3 } & $($ Mean $\pm \mathrm{SD})$ & $($ Mean $\pm \mathrm{SD})$ \\
Specific time to boil $\left[\mathrm{min} \mathrm{L}^{-1}\right]$ & $7.4 \pm 0.70$ & $10.6 \pm 0.10$ \\
Specific fuel consumption $\left[\mathrm{g} \mathrm{fuel} \mathrm{L}^{-1}\right]$ & $13.7 \pm 0.30$ & $14.8 \pm 0.10$ \\
Specific CO emission $\left[\mathrm{g} \mathrm{CO} \mathrm{L}^{-1}\right]$ & $0.78 \pm 0.24$ & $0.76 \pm 0.10$ \\
Thermal efficiency at high setting [\%] & $60 \pm 1.0$ & $53 \pm 1.0$ \\
Fire power & $1.4 \mathrm{~kW}$ & $1.1 \mathrm{~kW}$ \\
\hline
\end{tabular}

Adopted after Makonese et al., 2012 


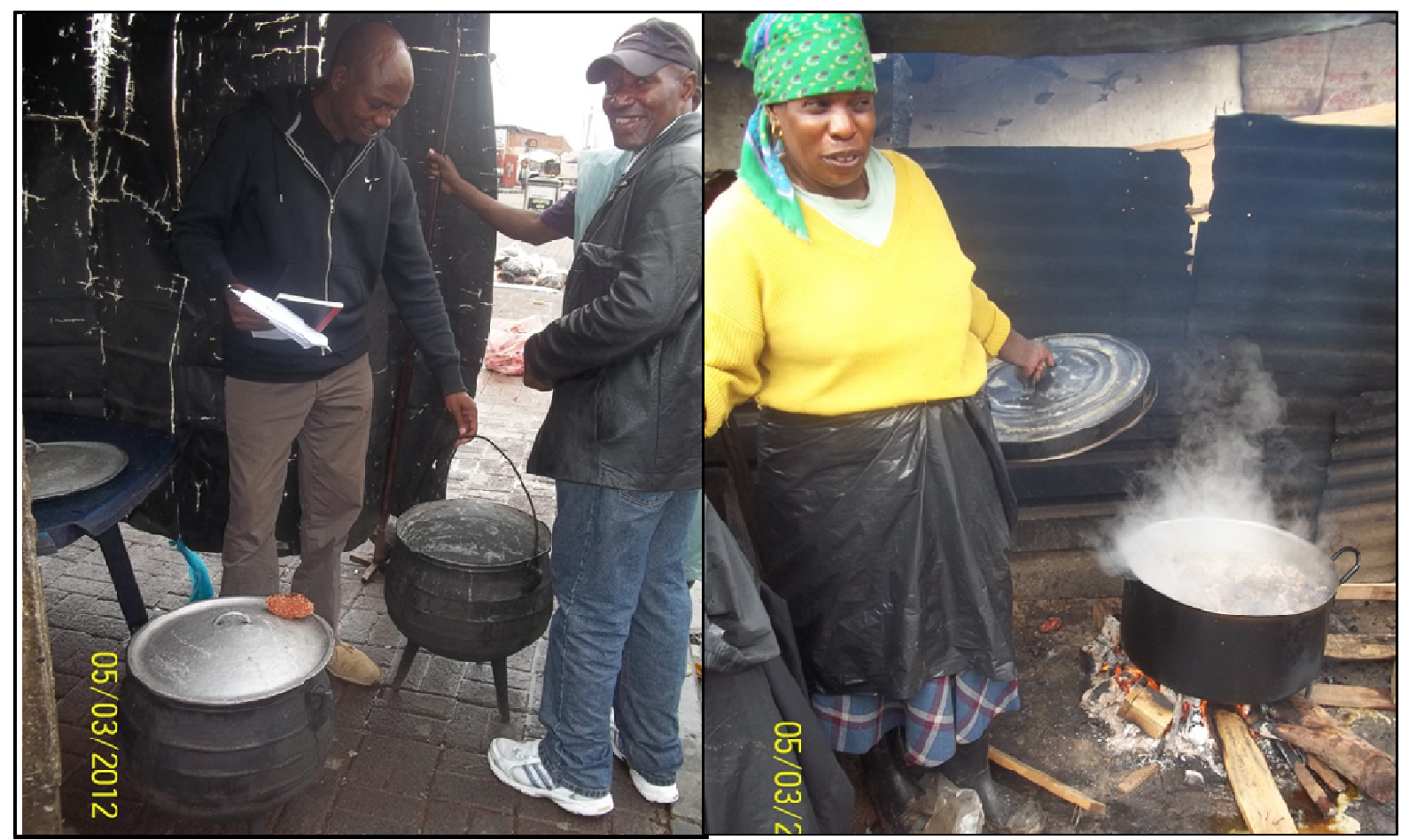

Figure 1. Image of regular cast iron pot and commercial cooking on three-stone wood fire (DK photos, 2012)

Among enterprises using LPG, three or four-burner stoves were most common, where they were often deployed alongside paraffin stoves; the latter being used for heat-intensive tasks (e.g. boiling water) that are more cost-effectively done with paraffin rather than LPG. The busier enterprises used up to ten paraffin stoves and two four-burner LPG stoves (Figure 2).

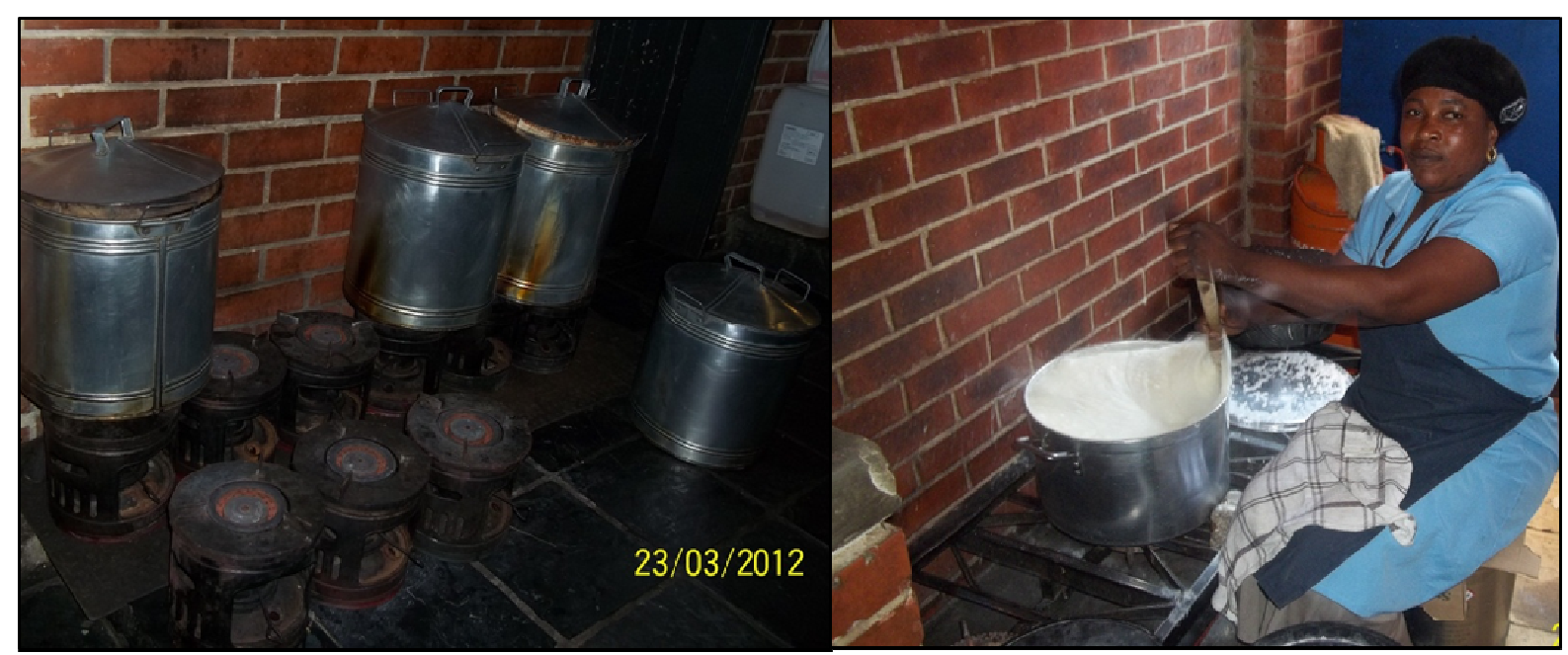

Figure 2. Paraffin and gas cooking in Alexandra Township (DK photos, 2012)

In businesses where multiple fuels were deployed, LPG was mentioned as the most important fuel, and the overall most preferred fuel to transition to. The attributes that make LPG a preferred fuel were stated as high power output/fast cooking, ease of use, and lack of smoke emissions; however, respondents' bemoan its ever-rising cost and periodic shortages. The energy technology preference seems to be positively correlated with typical fuel conversion efficiencies of common cooking technologies (Table 3). 
Table 3. Typical efficiencies of common energy carriers at final consumption stage of cooking

\begin{tabular}{lccc}
\hline \multicolumn{1}{c}{ Fuel source } & Energy content (MJ/kg) & $\begin{array}{c}\text { Typical conversion } \\
\text { efficiency (\%) }\end{array}$ & $\begin{array}{c}\text { Useful energy at final } \\
\text { consumption stage (MJ/kg) }\end{array}$ \\
\hline LPG & 45.5 & 60 & 27.3 \\
Paraffin (Pressure) & 43.0 & 55 & 23.6 \\
Paraffin (Wick) & 43.0 & 35 & 15.1 \\
Charcoal (efficient stove) & 30.0 & 30 & 9.0 \\
Coal (Bituminous) & 22.5 & 25 & 5.6 \\
Firewood (Efficient stove) & 16.0 & 25 & 4.0 \\
Firewood (Traditional stove) & 16.0 & 15 & 2.4 \\
\hline Ad & & &
\end{tabular}

Adopted after Sullivan and Barnes (2006)

When asked why they were using their current type of fuel/stove combination, a majority $(33.3 \%)$ of the respondents mentioned affordability as the main choice driver. This shows that energy technology choices depend on both product-specific and socioeconomic variables. Although a significant number of street cooking enterprises are still using inferior fuels and stoves, their aspirations are to graduate to use of modern fuels if and when they can afford them. The revealed and stated preferences indicate that LPG has the best combination of desirable attributes of a modern cooking fuel.

A majority (46.7\%) of the respondents is very satisfied with their current type of fuel/stove, while $30 \%$ are very dissatisfied (Figure 3). Main causes of dissatisfaction are smokiness (46.2\%) of the stove/fuel combination and inadequate energy supplies (23.1\%). Other problems for dissatisfaction include fuel shortages (esp. LPG but also paraffin), load shedding of electricity, smelly food due to paraffin fumes, and inability to cook when it rains (for wood and coal users). Some of the people using inferior fuels said they are satisfied since that is what they can afford and has sustained them thus far; nevertheless, they wish to evolve to use of modern energy technologies. According to $86.7 \%$ of the respondents, the most important feature they desire in an energy technology is high energy output for fast cooking.

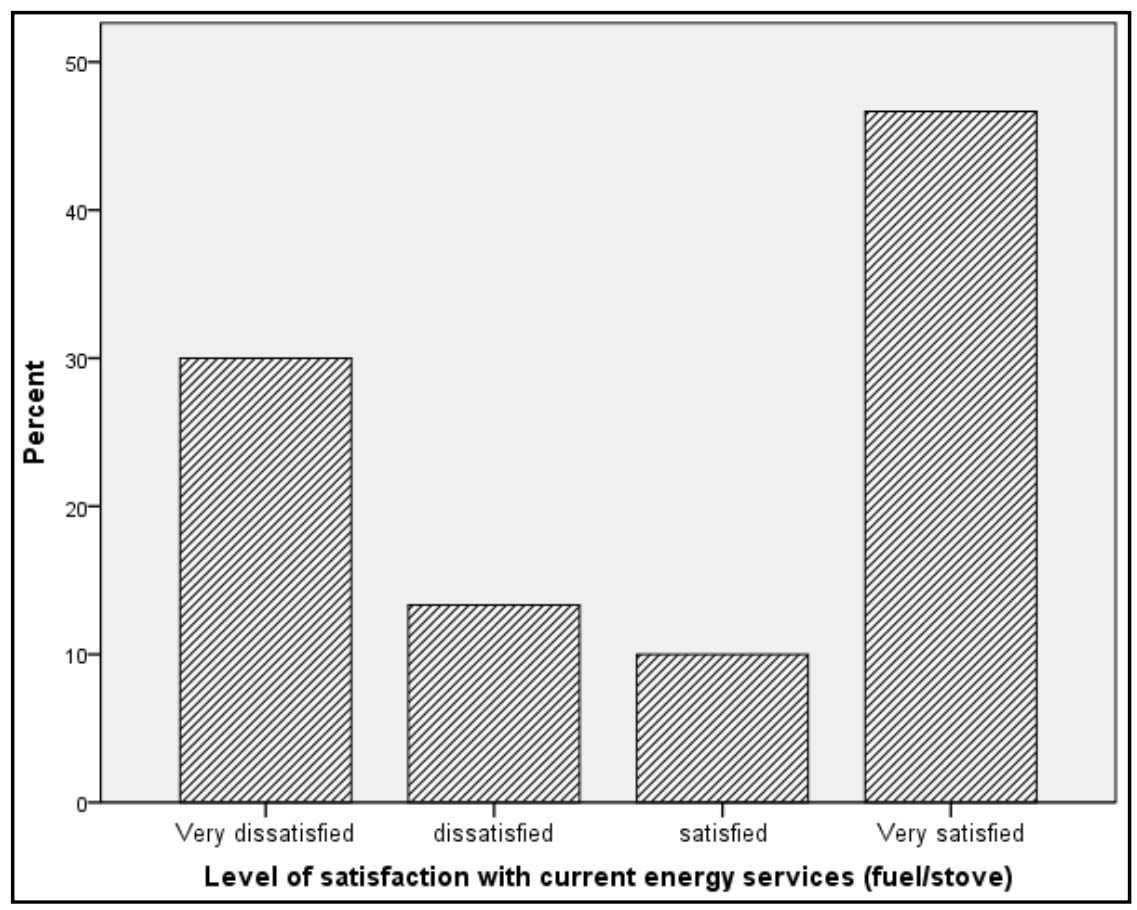

Figure 3. Responses on satisfaction with current fuel/stove combination 


\subsection{Energy Expenditure and Business Details}

The average weekly energy expense for the enterprises is R235 \pm 193 , with a maximum of R1030 and a minimum of R30. One business depended wholly on collected wood while the one with the minimum expenditure of R30 used only three litres of paraffin per week.

Most of the respondents have been in the particular business for longer than 4 years, with an average period of 11 years, minimum and maximum of 2 and 27 years respectively. A majority of the respondents $(60 \%)$ said that they were satisfied with the performance of their businesses. In particular, one respondent said that she was happy with her business because through its proceeds she has managed to educate her child up to university.

The respondents voiced unanimous opinion that in order for their businesses to attain growth, better structures/shelters $(70 \%)$ are needed so that they can work regardless of the weather and for some, to have sitting space for customers. After a proper operational structure, funding (30\%) was mentioned as a second most important necessity for growth of the street cooking businesses, while $20 \%$ of the respondents felt that an LPG stove would improve operations. Only one respondent felt that a cleaner burning wood stove would make a difference. Among those who mentioned capital injection as a prerequisite for further growth was Mrs. X, who said that she needed funding to buy bigger pots for making pap, which she is not serving now yet it is in high demand.

A majority $73.3 \%$ of the sampled businesses had one to two workers, often made up of the owner and one employee or just the owner working alone. About $34.5 \%$ of the businesses earned over R1500 per week with a maximum of R7000 and a minimum of R400. Around $45.5 \%$ of the businesses operated on open-road spaces (free occupation) with an equal number operating on rented premises (average monthly rent R270). The open-road premises consisted of a makeshift structure made up of a canvas canopy supported by four poles and no walls (Figure 4). Some of the entrepreneurs operating on the makeshift structure rented stores for overnight storage of their valuables at R150 per month.
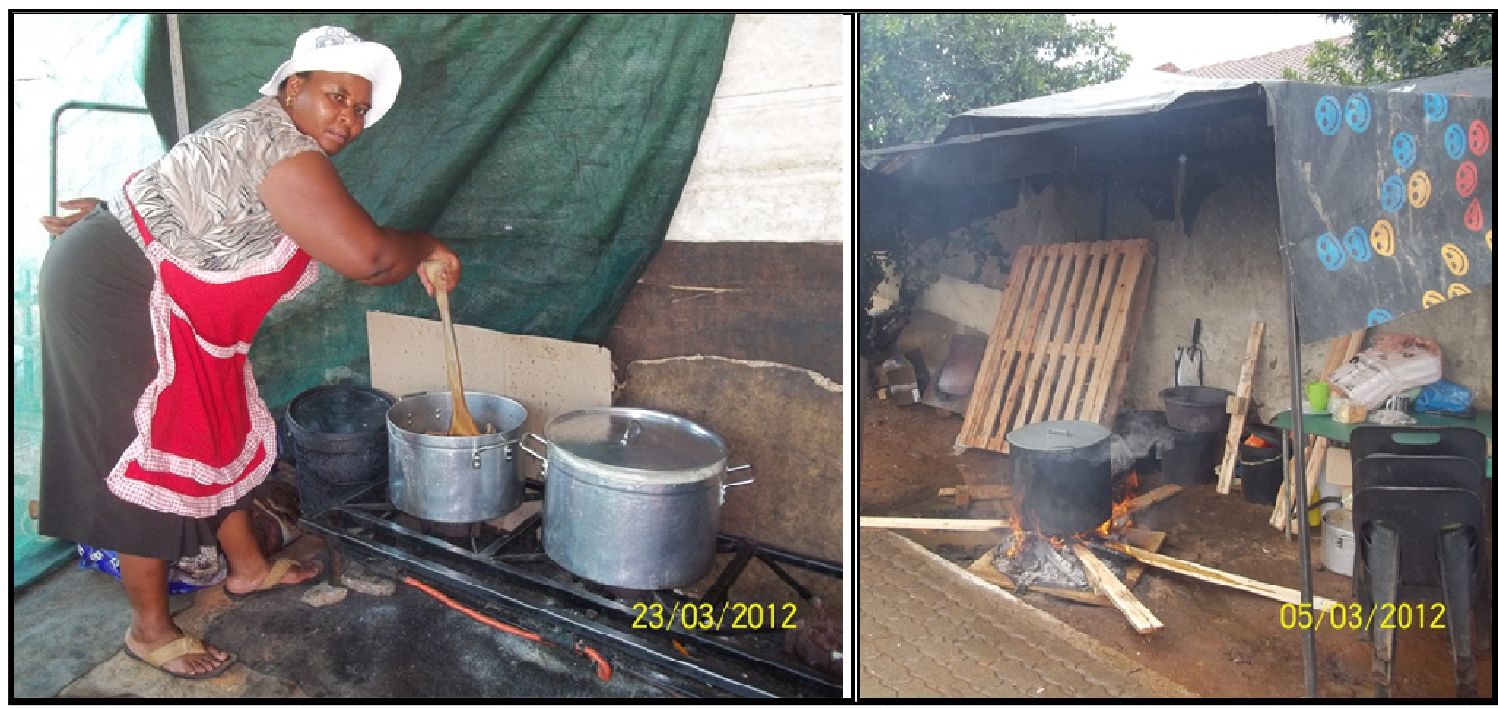

Figure 4. Images of informal business premises, Alexandra Township, Johannesburg (DK photos, 2012)

When asked whether they kept a record of their business transactions, a majority $63.3 \%$ said they did not. For those who kept records, it was mainly to track purchases and daily sales. Business proceeds were banked in personal accounts. None of the businesses had ever received a bank loan; however, several of the businesses said they had received a financial boost from a friend or relative, mainly for start-up or upgrade. It was clear to the researcher that the businesses require skilling, capitalisation, and proper operational structure so as to grow to the next level. Such expansion would create opportunities for more workers and higher profits for owners.

Most of the respondents were of the female gender (86.2\%) with a median sample age of 31-40 years (48.3\%) and an education level of grade 9-10. General feedbacks include complaints from members of the public that the street cooking businesses are polluting the ambient air and also dirtying the streets. The owners of the businesses felt that these complaints are borne out of jealousy. One business operator complained that the metro police kept 
confiscating her brazier (imbaula) and now she has to light open fires on the ground. She highlighted the fact that the street vendors are doing an honest business and should be assisted to scale-up rather than being frustrated.

\subsection{Energy Evolution, Business Transformation}

Every human community has a specific character, identity, a certain manner of existence, in which its long-term residents also partake, accepting as their own its problems and virtues (Rose, 1991). In Alexandra Township, public cooking (and eating) in open-air spaces is an accepted norm. The demand for the delicacies is far higher than the supply as most "restaurants" have their main meal of the day sold out by $2 \mathrm{pm}$ in the afternoon. The researchers witnessed many a forlorn looks as hungry clients turned up to eat and were told the food had run out. As advanced by McCannel (Rose, 1991), a community is a crucible that forms a new kind of human being and a new kind of social conscience. There are no exotic fast-food outlets inside the sprawling township; instead the people make do with street delicatessens that serve predictable local menus.

The study has highlighted a thriving informal business sector that yearns for a tailored assistance in order to attain growth. So far the sector has reached its current level of transformation without tangible help from institutions tasked with assisting small businesses. The findings show that lack of proper premises for cooking and serving customers is the major handicap, followed by inadequate energy services. Although some modern stalls have been put up by private developers near the commercial and comparatively well-off neighbourhood of PanAfric mall, these are only available to a negligible number of traders. Perhaps City of Johannesburg should adopt the scaled-up model of market stalls that has been instituted by the City of Cape Town for its street vendors (Figure 5). Such stalls could be delivered with a modern cooking system (LPG kit - four plate stove and cylinder) on tenant purchase or rental basis.

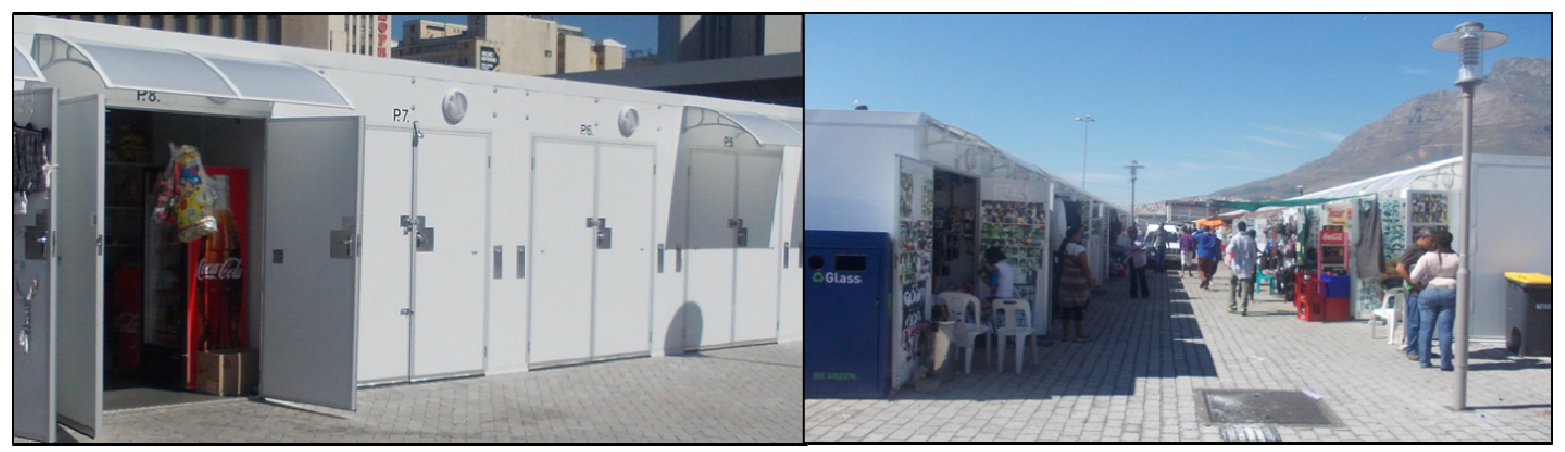

Figure 5. Image of market stalls, Station Deck, Cape Town (Taffy Photos, 2012)

An energy transition in the informal cooking businesses is an important transformation that would address human and environmental health. Three main determinants have been identified in the transition from traditional to modern energy use - fuel availability, affordability and cultural preferences (IEA, 2002). Advantages for an energy transition in street cooking businesses are job creation, economic growth, opportunities to earn carbon finance, and cleaner air. Barriers to the energy transition include cost of alternative energy technologies, lack of awareness among street vendors, lack of governmental support, inadequate fuel supplies, and lack of robust technical options. At the moment only LPG technology appears well resolved for commercial cooking. It is important to factor distribution dynamics in any energy transition models because lack of an effective distribution network makes modern energy technologies unavailable even to people that could have afforded them. Opportunities for tackling issues of modern energy affordability in the informal business sector could come from Energy Service Companies (ESCOs), who would act as risk takers (Beck \& Martinot, 2004). In South Africa, Eskom could work with local government and Department of Trade and Industry to facilitate energy transition and business transformation in the SMME sector.

One of the key outcomes of the UN World Commission on Environment and Development was that poor people depend more on natural resources for survival (World Commission on Environment and Development, 1987). Poverty then is a key driver of environmental destruction, either due to unsustainable resource exploitation or pollution emanating from inefficient and archaic conventional energy technologies. We restate with amplification that Governmental policies must ensure the wide availability of clean and reliable energy services for productive uses. 


\section{Conclusion}

The study has demonstrated the challenges borne by the informal cooking enterprises as they struggle to grow the businesses amidst a huge energy burden and lack of proper premises. The fact that the businesses have endured for many years in the midst of huge odds indicates an inherent potential in the business case and sheer resilience on part of the entrepreneurs. These are important strengths that the relevant role players should build on in order to attain the much needed socioeconomic growth. As attested by the operators, the businesses have enabled them to feed and educate their families without overly relying on government subsidies.

The cooking businesses aspire for modern energy, mainly driven by LPG; however cleaner institutional-type wood and paraffin stoves could be a stop-gap measure in the interim. The researcher was pleasantly surprised to find that the entrepreneurs find LPG a better alternative to the solid fuels and not electricity which has a high load factor and therefore not sustainable for cooking activities. Perhaps the municipality and relevant role players should find ways of facilitating the enterprises' access to LPG equipment. Although the study has focussed on energy needs of conventional fuels driven cooking businesses, it should be appreciated that wide availability of motive power is equally necessary for food/drinks refrigeration and other informal business activities.

The respondents ranked main problems that beset their businesses as lack of proper premises, capital and reliable clean energy sources. This again calls on the relevant arms of government to work with the stakeholders and come up with workable solutions relevant to the actual, rather than imputed needs of the functioning businesses. Regarding the provision of appropriate premises, the study recommends for City of Johannesburg to adopt the market stalls model implemented by the City of Cape Town. The findings of this study highlight the need for skilling in enterprise management, a service that should be readily available from the myriad of governmental and private sector organisations operating in the small businesses sector around Johannesburg.

It is established that higher consumption of commercial energy leads to increased use of modern fuels and less reliance on biomass (Jiang \& O'Neill, 2004; Yao, Chen, \& Li, 2012). Therefore, household energy policies in developing countries must incorporate productive energy services alongside the residential needs. Such an approach would ensure a progressive attainment of energy sustainability as envisioned by the UN General Assembly in its declaration of the International Year of Sustainable Energy for All (UN, 2012).

\section{Acknowledgements}

We wish to thank Vincent Molapo, Daniel Mogale and Petunia Mashigo for their contributions as enumerators. This project was funded through a University of Johannesburg research grant to SeTAR Centre and the National Research Foundation [NRF] Focus Area grant Energy as a Key Technology for a Sustainable Megacity City Gauteng (No. FA2006022800010). We are grateful for the cooperation demonstrated by the respondents who agreed to be interviewed amidst their busy routines. Our gratitude goes to Peter Njau for editorial comments.

\section{References}

Adam, F. (2010). Free basic electricity: A better life for all. Earthlife Africa, Johannesburg. Retrieved March 20, 2012, from http://www.earthlife.org.za/?page_id=1204

Beck, F., \& Martinot, E. (2004). Renewable energy policies and barriers. Encyclopaedia of Energy, Academic Press, 1-22.

Bennet, S. J., \& Pearson, P. J. (2009). From petrochemical complexes to biorefineries? The past and prospective co-evolution of liquid fuels and chemicals production in the UK. Chemical Engineering Research Design, 87, 1120-1139. http://dx.doi.org/10.016/j.cherd.2009.02.008

Bhorat, H., van den Berg, S., \& Aardt, C. (2003). Poverty and inequality in South Africa - current trends, issues and future policy options. Retrieved March 9, 2012, from http://www.sarpn.org/documents/d0000649/P661 -Povertyreport3b.pdf

Bond, P. (2000). Cities of Gold Townships of Coal: Essays on South Africa's new urban crisis. Asmara: Africa World Press Inc.

City of Johannesburg. (2012). Region E demographics and Alexandra Renewal Project. Retrieved from http://www.joburg.org.za/index.php?option=com_content\&task=view\&id=177\&Itemid=168\&limitstart=1

Department of Minerals and Energy. (2003). Electricity basic services support tariff policy. Government Gazette, Vol. 457, No. 25088, Pretoria.

Goldemberg, J., Johansson, T., Reddy, A., \& Williams, R. (2004). A global cooking fuel initiative. Energy for Sustainable Development, VIII, 5-12. http://dx.doi.org/10.1016/S0973-0826(08)60462-7

Haas, R., Nakicenovic, N., Ajanovic, A., Faber, T., Kranzl, L., Muller, A., \& Resch, G. (2008). Towards 
sustainability of energy systems: A primer on how to apply the concept of energy services to identify necessary trends and policies. Energy Policy, 36, 4012-4021. http://dx.org/10/1016/j.enpol.2008.06.028

International Energy Agency. (2002). World Energy Outlook 2002. OECD Publishing.

Jiang, L., \& O'Neill, B. C. (2004). The energy transition in rural China. Int. J. Global Energy Issues, 21(1/2), $2-26$.

Kimemia, D. K., \& Annegarn, H. J. (2011). An urban biomass energy economy in Johannesburg, South Africa. Energy for Sustainable Development, 15, 382-387. http://dx.doi.org/10.1016/j.esd.2011.10.002

Makonese, T., Pemberton-Pigott, C., Robinson, J., Kimemia, D. K., \& Annegarn, H. J. (2012). Performance evaluation and emission characterisation of three paraffin stoves using a Heterogeneous Testing Protocol (HTP). Energy for Sustainable Development, 16, 344-351. http://dx.doi.org/10.1016/j.esd.2012.06.002

Meadows, K., Riley, C., Rao, G., \& Harris, P. (2003). Modern Energy: Impacts on Micro-enterprises. A report produced for UK Department for International Development. Retrieved July 20, 2012, from http://www.dfid.gov.uk/r4d/PDF/Outputs?Energy/R8145-Litrev.pdf

Miller, B., \& Tillman, D. (2008). Combustion engineering issues for solid fuel systems. London: Academic Press.

National Regulator for Compulsory Specifications. (2009). Consumers warned against the purchasing of unsafe non-pressure fuelled cooking stoves and heaters. Retrieved April 8, 2010, from www.nrcs.org.za/content.asp?subID $=56 \#$

Njiro, E., Mazwai, T., \& Urban, B. (2010). A situational analysis of small businesses and enterprises in the townships of the Gauteng Province of South Africa. Paper presented at the First International Conference for Small Business Development, 20-25 January 2010, University of Johannesburg. Retrieved from http://www.uj.ac.za/EN/Faculties/management/departments/CSBD/Documents/2010\%20CSBD\%20Confere nce\%20Docs/Intro_NjiroMazwaiUrban.pdf

Rhodes University and University of Fort Hare. (2008). Energy requirements of SMMEs in the Eastern Cape. Retrieved March 10, 2012, from www.saneri.org.za/docs/Final_Report.pdf

Rogerson, C. M. (2006). Developing SMMEs in peripheral spaces: the experience of Free State Province, South Africa. South African Geographical Journal, 88, 66-78. http://dx.doi.org/10.1080/03736245.2006.9713848

Rose, D. (1991). Energy transitions and the local community - a theory of society applied to Hazleton, Pennsylvania. Philadelphia: University of Pennsylvania Press.

Shrestha, R. M., Kumar, S., Martin, S., \& Limjeerajarus, N. (2006). Role of renewable energy for productive uses in Thailand. Retrieved from www.gnesd.org/downloadables/RETs/AIT\%20RETs\%20Final\%20draft.pdf

Smil, V. (2010). Energy transitions: history, requirements, prospects. Santa Barbara, C.A, Praeger.

South Africa, National Energy Act. (2008). Act No. 34 of 2008. Government Gazette, Vol. 521, No. 31638, Cape Town.

Takama, K., Lambe, F., Johnson, F., \& Arvidson, A. (2011). Will African consumers buy cleaner fuels and stoves? A household energy economic analysis model for the introduction of Bio-Ethanol cooking stoves in Ethiopia, Tanzania, and Mozambique. Stockholm Environmental Institute, Sweden. Retrieved January 10, 2012, from http://www.sei-international.org/publications?pid=1867

United Nations. (2012). International Year of Sustainable Energy for All. Retrieved July 31, 2012, from www.un.org/en/events/sustainableenergyforall

Weijermars, R., Taylor, P., Bahn, O., Das, S. R., \& Wei, Y. (2012). Review of models and actors in energy optimization - can leader visions and decisions align with optimum model strategies for our future energy systems? Energy Strategy Reviews, 1, 5-18. http://dx.doi.org/10.1016/j.esr.2011.10.001

World Commission on Environment and Development. (1987). Our common future. Geneva, UN. Retrieved July 7, 2012, from http://www.un-documents.net/our-common-future.pdf

Yao, C., Chen, C., \& Li, M. (2012). Analysis of rural residential energy consumption and corresponding carbon emissions in China. Energy Policy, 41, 445-450. http://dx.doi.org/10.1016/j.enpol.2011.11.005

\section{Notes}

Note 1: By 2011 standards, poverty in South Africa referred to those earning less than R430 [ 60 USD] per month. 